Revista Tecnologia e Ambiente, v. 21, 2014, Criciúma, Santa Catarina. ISSN: 1413-8131

(versão impressa) ISSN: 2358-9426 (versão eletrônica)

\title{
A FACE DO ESPAÇO PRISIONAL
}

\section{THE FACE OF INPRISONING SPACE}

\section{RESUMO}

\author{
Marília Tavares Dávila ${ }^{1}$ \\ Teresinha Maria Gonçalves ${ }^{2}$
}

O objetivo central deste trabalho consistiu em realizar um levantamento sobre o perfil dos reincidentes e as possíveis causas da reincidência criminal dos reclusos no Presídio Regional de Criciúma (PRC), SC. Pretendeu-se realizar um levantamento de dados documentais sobre os reincidentes no crime; buscar informações sobre a estrutura do PRC; conhecer os programas de ressocialização desse local; levantar dados sobre o perfil socioeconômico, sobre o histórico criminal e os motivos que levaram os apenados a reincidirem no crime, além de coadunar os dados obtidos à luz da psicologia social. $\mathrm{O}$ estudo pretendeu expor aspectos relacionados à questão da reincidência no crime, a partir do perfil dos reclusos do PRC, bem como os aspectos que envolvem essa problemática. As técnicas utilizadas foram pesquisa documental, de campo e bibliográfica. A pesquisa de campo foi de cunho quali-quantitativo e do tipo descritiva. Os dados documentais levantados referem-se aos registros contidos no departamento jurídico do PRC sobre os reincidentes no crime. Para realizar a pesquisa de campo foi aplicado um questionário com 15 questões sobre estes reincidentes, além de uma entrevista com o gestor sobre os programas de ressocialização existentes na instituição, os quais foram importantes para responder aos objetivos propostos.

Palavras-chave: Espaço prisional, espaço extremo, identidade.

\section{ABSTRACT}

The main goal of this work is conducting a survey on the profile of recidivists and the possible causes of criminal recidivism, in the Criciuma's, SC regional Jail. Specifically we wanted to conduct a survey of documentary data about criminal recurrence in delinquency, seek information about the structure of the institution, know about resocialization programs, in place to collect data on the socio-economic profile, criminal history and the reasons the convicts recall in crime, beside exposing the data to the social psychology. The study tried to outline the aspects related to the tendency on convicts of Criciumas's Regional Jail incidence in crime, as well as questions involving this issue. The techniques used were: Documentary research, Field research and Literature documentation. The field research was of quantitative and qualitative nature and descriptive type. The documentary data was referred to the records contained in the legal department of the PRC, about recidivists. To conduct the field research, a questionnaire with 15 questions on recidivists was applied, in addition to an interview with the supervisor, about the existing rehabilitation programs in the institution that were consider important to the proposed objectives.

\footnotetext{
1 Universidade do Extremo Sul Catarinense - UNESC - Programa Institucional de Bolsas de Iniciação Científica (PIBIC), Criciúma/SC - email: marylia_davila@yahoo.com.br

${ }^{2}$ Universidade do Extremo Sul Catarinense - UNESC - Programa de Pós Graduação em Ciências Ambientais (PPGCA), Criciúma/SC - e-mail: tmg@unesc.net
} 
Revista Tecnologia e Ambiente, v. 21, 2014, Criciúma, Santa Catarina. ISSN: 1413-8131 (versão impressa) ISSN: 2358-9426 (versão eletrônica)

Keywords: Prison space, extreme environment, identity.

\section{INTRODUÇÃO}

O presente trabalho apresenta um levantamento do perfil dos reincidentes e as possíveis causas da reincidência criminal no Presídio Regional de Criciúma (PRC), sob a ótica da Psicologia Social, e teve como público-alvo os reclusos reincidentes no crime que estavam presentes nos registros do Presídio Regional de Criciúma, Santa Catarina, durante o levantamento de dados documentais realizado na instituição no mês de outubro de 2012.

A escolha por esse tema vem de um longo percurso da acadêmica durante o curso de graduação em Psicologia na Universidade do Extremo Sul Catarinense (UNESC), em busca de esclarecer as indagações e indignações sobre a realidade do sistema prisional. A motivação da acadêmica em relação ao tema começou a surgir já nos primeiros debates sobre a história das prisões e o poder disciplinar, no olhar de Foucault, que aconteceram durante as fases iniciais do curso de psicologia.

A caminhada para a busca do entendimento e reflexões sobre todos esses questionamentos motivaram um projeto de iniciação científica (PIBIC ${ }^{3}$ ) sobre a "Identidade de papel de um grupo de apenados no Presídio Regional de Criciúma (PRC)”, realizado no ano de 2012, o qual serviu para que mais questionamentos fossem surgindo e encaminhando a acadêmica a vivenciar um estágio de Psicologia Organizacional e do Trabalho com os trabalhadores da instituição prisional e, posteriormente, um estágio em Psicologia Social, possibilitando conhecer a realidade das mulheres que estavam em situação de prisão naquele local.

O Programa Institucional de Bolsas de Iniciação Científica (PIBIC) é uma iniciativa do CNPq - Conselho Nacional de Desenvolvimento Científico e Tecnológico, que apoia a Iniciação Científica desenvolvida nas instituições de ensino e/ou pesquisa com o auxílio de bolsas para estudantes de graduação envolvidos em pesquisa científica.

Todas essas vivências sobre a realidade do sistema prisional no âmbito da Psicologia Social, ciência que norteou grande parte dos trabalhos realizados pela acadêmica

\footnotetext{
${ }^{3}$ Programa Institucional de Bolsas de Iniciação Científica
} 
Revista Tecnologia e Ambiente, v. 21, 2014, Criciúma, Santa Catarina. ISSN: 1413-8131

(versão impressa) ISSN: 2358-9426 (versão eletrônica)

durante esse percurso, mostraram infinitas possibilidades e necessidades que merecem ser discutidas.

Antes de delimitar o assunto, a acadêmica consultou diversos temas de monografias realizadas nos cursos de Psicologia e Direito da UNESC, observando que não havia dados sobre a reincidência criminal. Isso chamou sua atenção, pois, durante os estágios realizados no Presídio Regional de Criciúma, foi observado que grande parte das mulheres que estavam presas havia passado por alguma instituição prisional mais de uma vez. Além disso, essa questão do retorno dos reclusos à prisão era algo constantemente relatado pelos trabalhadores em conversas informais.

Sendo assim, a acadêmica entende a questão da reincidência como um tema relevante a ser pesquisado no PRC. A pergunta que norteou a realização desta pesquisa foi: Qual o perfil dos reincidentes e os motivos da reincidência criminal dos reclusos no PRC?

De acordo com Bauman (1999), grande parte dos reclusos vivencia situações de vulnerabilidade social, o que, com o advento da pós-modernidade, traz novas formas de reconhecimento do sujeito, apontando o consumo como fator principal. Sendo assim, a hipótese inicial para o problema da pesquisa foi de que os reincidentes do PRC buscam se enquadrar no perfil exigido pela sociedade por intermédio da criminalidade.

Para responder ao problema da pesquisa, o objetivo geral do trabalho proposto foi realizar um levantamento sobre o perfil dos reincidentes e as possíveis causas da reincidência criminal dos reclusos do PRC, SC.

Entre os objetivos específicos contemplados estão: a realização de um levantamento de dados documentais sobre os reincidentes no crime; a busca de informações sobre a estrutura da instituição prisional e dos programas de ressocialização existentes no local; o levantamento de dados socioeconômicos dos reincidentes; a verificação do histórico criminal dos apenados que retornaram ao crime e a identificação dos motivos de sua reincidência no crime. Após o resultado final, foram analisados os dados à luz da Psicologia Social.

Para o alcance dos objetivos propostos na pesquisa, foi realizado um questionário autoaplicativo construído a partir de pesquisas realizadas por Prá et al. (2004), Neto e Baumer (2008) e Ferreira (2011). 
Revista Tecnologia e Ambiente, v. 21, 2014, Criciúma, Santa Catarina. ISSN: 1413-8131

(versão impressa) ISSN: 2358-9426 (versão eletrônica)

A fundamentação teórica, baseada na Psicologia Social, também demonstrou um papel importante para o entendimento do tema pesquisado.

A Psicologia Social estuda o processo das relações sociais entre os indivíduos, pois se entende que é nesse contato que o sujeito se constitui e ao mesmo tempo é constituído pelo meio. Para entender essas relações, ela transita por diversas áreas, principalmente as das ciências humanas.

\section{RESSOCIALIZAÇÃO}

No dicionário de língua portuguesa, Ferreira e Ferreira (2009, p. 1746) conceituam o verbo ressocializar como "tornar a socializar", porém, definir um conceito que expresse a ressocialização na atualidade é algo que se configura muito mais complexo.

Partindo do princípio de que ressocializar é auxiliar o sujeito a se socializar, entende-se que para isso acontecer é importante que o indivíduo reincorpore o sentido de ser social. Para Pinto (2006), o processo de socialização ocorre quando o sujeito internaliza alguns conceitos sobre valor, crença de uma cultura, construção de um mundo histórico para si, humanização e significações. Para isso, é importante que haja a interação do sujeito com o meio, sendo que a construção dessa socialização, de acordo com Berger e Luckmann (2012, p. 175), pode ser primária ou secundária.

A socialização primária é a primeira que o indivíduo experimenta na infância, e em virtude da qual se torna membro da sociedade. A secundária é qualquer processo subsequente que introduz o indivíduo já socializado em novos setores do mundo, objetivo de sua sociedade.

Tendo em vista a questão da ressocialização prisional, entende-se que esse processo precisa levar em conta todas as dimensões sociais do sujeito, pois este vem para a instituição com alguns conceitos já internalizados. A prisão deveria contemplar a socialização secundária, permitindo ao sujeito o contato com uma nova realidade em que pudesse construir novas significações, com o objetivo de ressocializá-lo.

Porém, o que se percebe, atualmente, nas instituições prisionais é o desrespeito com os direitos relativos à subjetividade do sujeito que está preso, sendo que este muitas vezes é humilhado e agredido nessas instituições, as quais teriam como foco a ressocialização 
Revista Tecnologia e Ambiente, v. 21, 2014, Criciúma, Santa Catarina. ISSN: 1413-8131

(versão impressa) ISSN: 2358-9426 (versão eletrônica)

(ASSIS, 2007). A partir do momento em que o sujeito entra em uma instituição penal, uma barreira com o mundo externo lhe é colocada, ocorrendo o que Goffmann (2007) chama de "a mutilação do eu". O indivíduo é exposto a uma situação de coação, violência e desrespeito à sua singularidade, acabando por perder a referência como ser humano e entrando em um processo de "mortificação do eu".

Para Goffmann (2007), mortificação e mutilação do eu possuem o mesmo sentido. Sendo que se referem à negação da subjetividade do sujeito quando ele entra em uma instituição total. Isso se expressa pelas regras que precisa cumprir sem questionar, incluindo a padronização de roupas, o cumprimento de regras e o abandono de seus valores e significações anteriormente interiorizados.

Foucault (2010) vê as instituições penitenciárias como uma forma de punição e controle social, sendo que por meio do poder disciplinar elas produzem indivíduos, apropriando-se destes por meio de estruturas de poder. Dessa forma, o sujeito é "adestrado" para que aja de forma dócil quando voltar à sociedade. Essa forma instituída diz que as pessoas devem seguir as regras da sociedade e estar dentro dos padrões, caso contrário, serão punidas, se não com a prisão, com o fracasso, o rebaixamento, a exclusão social.

Para Carlen (2007, p. 1008), atualmente, a prisão "enclausura pessoas contra a vontade, perverte necessariamente (não acidentalmente)" utilizando do discurso como função terapêutica que, atualmente, resulta no fracasso das tentativas de reforma prisional. Fernandes (2000) faz uma analogia do sistema prisional que o Brasil possui atualmente: o indivíduo que é preso por roubar e passa pela instituição prisional, em muitos casos, volta como homicida, demonstrando, assim, a precariedade do sistema.

A sociedade, por sua vez, de acordo com Assis (2007), dificulta ainda mais nessa questão da ressocialização, pois vê o cárcere como "um lixo humano", sem levar em conta que aquele sujeito que lá se encontra é, muitas vezes, resultado da desigualdade social produzida pela própria sociedade.

As instituições prisionais trazem o reflexo das características típicas da sociedade, sendo elas o egoísmo e a violência ilegal existentes nas relações sociais, levando o sujeito mais frágil a um papel de exploração e submissão (BARATTA, 1997). 
Revista Tecnologia e Ambiente, v. 21, 2014, Criciúma, Santa Catarina. ISSN: 1413-8131

(versão impressa) ISSN: 2358-9426 (versão eletrônica)

Há de ser questionado para qual sociedade se pretende incluir o indivíduo que sai da prisão. Não seria o caso de, antes, repensar os valores e os comportamentos praticados na sociedade em que se pretende incluir o condenado? Talvez, com isso, se possa atingir o mecanismo de exclusão, bem como identificar com mais propriedade onde estão e quais são os tipos de violência existentes (HOFFMANN, 2009, p. 275).

A globalização expressa essa problemática trazida por Baratta e Hoffmann. As classes vulneráveis acabam por se configurarem como uma "válvula de escape" para aqueles que estão no topo do controle social. É mais fácil e cômodo culpabilizar e estigmatizar os que estão em uma camada social inferior e que na verdade são reflexos da produção da desigualdade social dos ditos "colarinhos brancos", que acabam sendo camuflados, gerando um jogo de poder onde quem acaba sofrendo as consequências mais sérias são as camadas mais vulneráveis da sociedade (BAUMANN, 1999).

\section{PSICOLOGIA SOCIAL}

A Psicologia Social é uma área de estudo sobre o processo das relações sociais, que busca entender a maneira como agimos frente a determinadas situações, constituindo e sendo constituída no movimento dessas interações existentes na sociedade. Entende-se que é a partir do contato que o sujeito vai construindo a sua singularidade e ao mesmo tempo irá contribuir para a construção do meio, sendo esse processo o principal foco da Psicologia Social (BOCK et al., 2008; MYERS, 2000; RODRIGUES, 1998).

A Psicologia Social teve como base para a sua constituição a contribuição de outras ciências, entre elas se destacam a antropologia, a sociologia, a biologia e a própria psicologia (SOUZA, 2005). Todas essas ciências foram importantes para que a Psicologia Social pudesse estudar e entender as relações entre sujeito, grupo e sociedade.

\section{A INFLUÊNCIA DA PÓS-MODERNIDADE NA SITUAÇÃO DE CÁRCERE}

O debate pós-moderno traz questões sobre o sujeito e a subjetividade, com críticas e discussões frente às influências deixadas pela modernidade. As questões dos signos e representações, bem como a globalização, são trazidas por Gonçalves (2001) como problemáticas da pós-modernidade, reflexo da modernidade. Porém, a expressão nesses 
Revista Tecnologia e Ambiente, v. 21, 2014, Criciúma, Santa Catarina. ISSN: 1413-8131

(versão impressa) ISSN: 2358-9426 (versão eletrônica)

dois momentos vai se configurando de forma diversificada.

A globalização na modernidade pode ser entendida como uma estratégia de homogeneização de diversos aspectos, principalmente das culturas. Com a globalização há uma aproximação entre várias culturas no mundo, viabilizando a informação, o acesso e padronização de diferentes modelos culturais. E, ao mesmo tempo, há uma apropriação de recursos de países subdesenvolvidos, submetendo-os à exploração dos países desenvolvidos, os quais impuseram os padrões de globalização (GIDDENS, 1991; CANCLINI, 2007).

Nos últimos anos, vem aumentando consideravelmente o número de prisões, reclusos e pessoas atingidas pela vulnerabilidade social. Bauman (1998) atribui essa questão ao processo de modernidade, sendo que, se antes o sujeito que estava desempregado era preparado para assumir uma função assim que possível, com a globalização há eliminação da mão de obra, já não há espaço para todos.

Junto com essa questão da globalização trazida pela modernidade vem à sociedade de consumo, difundida como o objeto central da vida do ser humano, ou seja, só é possível ser feliz, sentir-se bem e satisfeito se houver o consumo. Não há restrições, é importante arrumar uma forma para poder consumir. Essa condição da modernidade produz a criminalidade, sendo uma forma de excluir aqueles que não têm outros meios para conseguir entrar no padrão da sociedade de consumo (BAUMAN, 1998). Segundo este autor (1998, p. 57):

As margens incriminadas servem de esgoto para onde os eflúvios inevitáveis, mas excessivos e venenosos, da sedução consumista são canalizados, de modo que as pessoas que conseguem permanecer no jogo do consumismo não se preocupam com o estado da própria saúde.

Entende-se, assim, que a sociedade moderna permite que aquele que consome de forma "legalmente aceita" não precisa se preocupar com questões sociais, ele pode consumir à vontade e buscar com isso preencher aquilo que chama de "bem-estar", sem o peso na consciência. Já o criminoso, o pobre, o indigente, é assim porque escolheu; o consumista não precisa se preocupar com essa situação, pois ele sim atende às "regras do jogo" (BAUMAN, 1998).

Já a pós-modernidade vem com um novo propósito para a sociedade de consumo, o 
Revista Tecnologia e Ambiente, v. 21, 2014, Criciúma, Santa Catarina. ISSN: 1413-8131

(versão impressa) ISSN: 2358-9426 (versão eletrônica)

sujeito agora busca a heterogeneidade naturalizando as diferenças, o que gera a afirmação das desigualdades, tornando isso algo natural (GONÇALVES, 2001).

A Pós-Modernidade é traçada como a época das incertezas, das fragmentações, da troca de valores, do vazio, do niilismo, da deserção, do imediatismo, da efemeridade, do hedonismo, da substituição da ética pela estética, do narcisismo, da apatia, do consumo de sensações e do fim dos grandes discursos. (MORAES, 2004, p.1).

Se a sociedade de consumo no período da modernidade privilegiava o ter, sendo que os signos eram expressões do sujeito, por meio da linguagem e do discurso, atualmente, na pós-modernidade, isso vai muito além, "os signos agora passam a ter vida própria", sendo destaque na atual sociedade, fazendo até com que o sujeito desapareça (GONÇALVES, 2001, p. 59).

Essa nova realidade que vivenciamos na atualidade com a reafirmação das desigualdades sociais traz consequências ainda mais preocupantes para o sistema prisional. Frente a isso, de acordo com Bauman (1999, p. 120), a situação de cárcere configura-se como um processo de "rejeição simbólica e exclusão física", no qual o principal objetivo é fazer com que o sujeito aceite suas "imperfeições e inferioridade social".

Com o processo de exclusão, aquele que é excluído busca defender-se rejeitando quem o rejeita. Isso ocorre, na maioria dos casos, com expressões de violência, sendo esta uma das poucas maneiras de "poder prejudicar", reagindo contra o sentimento de esmagamento que sente frente a essa situação de exclusão (BAUMAN, 1999, p. 20).

\section{RESULTADOS E DISCUSSÕES}

A pesquisa realizada no Presídio Regional de Criciúma buscou conhecer o perfil dos reincidentes no crime, além das possíveis causas da reincidência criminal. Para alcançar esse objetivo, os resultados obtidos na pesquisa foram coadunados com reflexões de autores que transitam pela Psicologia Social.

Com os resultados obtidos e a análise foi possível perceber que a população do PRC confirma a exclusão social que há entre a população carcerária no sistema prisional brasileiro, o que vai ao encontro da hipótese inicial, que foi levantada para responder ao problema da pesquisa. 
Revista Tecnologia e Ambiente, v. 21, 2014, Criciúma, Santa Catarina. ISSN: 1413-8131

(versão impressa) ISSN: 2358-9426 (versão eletrônica)

Observa-se, porém, que essa exclusão existe antes mesmo de o sujeito entrar na vida do crime, sendo que a prisão apenas contribui para reafirmar ao sujeito que ele não pertence à sociedade.

Uma hipótese para os motivos que envolvem essa situação se refere às formas de “incluir” que são trazidas pela modernidade e reafirmadas na pós-modernidade. Essa forma estabelecida pela sociedade de consumo traz que "ter" tem mais valor que "o ser", a ética é substituída pela banalização da vida sendo o consumismo a principal forma de preencher o vazio interior do sujeito.

Lorenzer (1976) traz que um dos constitutivos do processo de subjetivação são os valores internalizados da sociedade. A individualidade segundo o autor, se constitui, então, em cada forma particular de interação. Nesta perspectiva se o apenado viveu a vida pregressa em ambiente hostil de violência e injustiças, num contexto de sociedade madrasta na perspectiva de Damergian (2001), ponderamos que o processo de produção da subjetividade foi prejudicado pelo contexto e pela forma com que o sujeito se valeu da sua pulsão de vida para adquirir, ou não uma valência positiva suficiente para manter-se integro, apesar de toda a hostilidade e desamparo em que viveu.

Diante do exposto podemos deduzir que a vida pregressa do apenado, deve ser levada em conta para se pensar num verdadeiro processo de ressocialização da pessoa com privação de liberdade. Dessa forma fica evidente a necessidade de mais programas de ressocialização prisional no PRC que possam ser acessados por toda a população carcerária, sendo que, no período da pesquisa, as mulheres eram mais privilegiadas nesse sentido do que os homens. Dados mostraram que o número de reincidência criminal na instituição é maior no sexo masculino do que no feminino, sendo uma hipótese o baixo número de projetos de ressocialização para os homens naquele local.

Outro dado importante observado no PRC foi quanto ao motivo da reincidência criminal, sendo que grande parte relacionou o retorno ao crime com o vício de drogas. Entende-se que a droga, na atualidade, é um problema de saúde pública. Sendo assim, é necessário repensar as formas de lidar com essa questão, pois, nas instituições penais, observa-se que não há nenhuma intervenção frente a essa problemática.

A realização desta pesquisa trouxe alguns questionamentos e reflexões sobre o 
Revista Tecnologia e Ambiente, v. 21, 2014, Criciúma, Santa Catarina. ISSN: 1413-8131

(versão impressa) ISSN: 2358-9426 (versão eletrônica)

sistema prisional de Criciúma, sendo assim, lanço algumas sugestões de pesquisa em relação ao PRC.

\section{MATERIAL E MÉTODOS}

\subsection{Tipo de Pesquisa}

A pesquisa caracterizou-se como documental, de campo e bibliográfica. É considerada documental devido aos dados obtidos nos registros dos reclusos reincidentes não terem recebido nenhuma intervenção de análise. Caracteriza-se como de campo porque a pesquisadora entrou em contato com a população a ser pesquisada para colher os dados (GIL, 1994).

A natureza da pesquisa é quantitativa e qualitativa. Quantitativa devido à aplicação de questionários com dados numéricos e mensuráveis. Qualitativa porque permite a exposição da opinião descritiva dos participantes em algumas questões (GIL, 1994).

A pesquisa também é considerada como descritiva, sendo que possibilitou à pesquisadora um levantamento das características da população pesquisada (LEOPARDI, 2001).

\subsection{População de Estudo}

A população da pesquisa foi constituída por todos os apenados reincidentes que constavam nos registros do PRC no início da aplicação de dados em outubro de 2012.

Foi utilizado como critério de inclusão na pesquisa ser considerado reincidente no crime, de acordo com os registros da instituição prisional; aceitar assinar o termo de consentimento livre e esclarecido e responder ao questionário aplicado pela pesquisadora.

\subsection{Amostra}

A amostragem da pesquisa foi censitária, pois buscou obter os dados relacionados à reincidência de todos os reclusos reincidentes que cumpriram pena no PRC durante o início da coleta de dados documentais em outubro de 2012.

\subsection{Procedimentos}

Inicialmente, foi realizado o contato com o gestor do PRC, explicitando o objetivo de se realizar uma pesquisa sobre a reincidência criminal com os reincidentes no crime. Foi mencionada a necessidade de se colher dados documentais, informações sobre estrutura e 
Revista Tecnologia e Ambiente, v. 21, 2014, Criciúma, Santa Catarina. ISSN: 1413-8131

(versão impressa) ISSN: 2358-9426 (versão eletrônica)

programas de reincidência existentes na instituição, além da aplicação de um questionário à população de apenados considerados reincidentes, de acordo com os registros daquele presídio.

Após a autorização do gestor, foi encaminhado um projeto para o Comitê de Ética, cujo problema da pesquisa apresentado era: Qual o número de reincidência de presidiários no PRC? A hipótese inicial era que esses números seriam altos devido ao baixo número de programas de ressocialização realizados na instituição, o que foi observado pela pesquisadora durante os estágios obrigatórios efetuados naquele local.

Como objetivo geral, a pesquisa buscava realizar um levantamento sobre a reincidência de presidiários no PRC, os quais cumpriam pena no local durante o período de realização da pesquisa.

Após a aprovação do Comitê de Ética, a acadêmica realizou a coleta de dados documentais na instituição prisional, bem como de informações sobre a estrutura e os programas de ressocialização no PRC.

O passo posterior da pesquisa foi a aplicação de um questionário aos reincidentes no crime constantes nos registros do PRC, que aceitaram participar da intervenção.

Os questionários começaram a ser aplicados na instituição no final do mês de outubro. Porém, a aplicação precisou ser interrompida na segunda semana do mês de novembro devido a um início de rebelião, atentado ${ }^{4}$ ao PRC e à sociedade de Criciúma. Quando permitiram que fossem retomadas as aplicações de questionários, já no início do mês de dezembro, cerca de 40 reincidentes já não estavam mais na instituição devido às transferências, à saída temporária ou ao cumprimento da pena.

O próximo passo foi analisar os dados da pesquisa por meio do software estatístico SPSS - Statistical Package for the Social Science, versão 18.0 para Windows. As respostas dos questionários foram passadas para esse software de forma numérica, sendo obtidas

\footnotetext{
${ }^{4}$ Durante o mês de novembro ocorreram ataques ao PRC, com ameaças aos trabalhadores do local e de tiros disparados contra a instituição. Além disso, houve incêndios de diversos ônibus na região de Criciúma, motivados por facções criminosas do PGC (Primeiro Grupo Catarinense), que supostamente comandaram os ataques de dentro do presídio. Esses ataques aconteceram em outra localidade de Santa Catarina (ESTRELA, 2012).
} 
Revista Tecnologia e Ambiente, v. 21, 2014, Criciúma, Santa Catarina. ISSN: 1413-8131

(versão impressa) ISSN: 2358-9426 (versão eletrônica)

tabelas com os resultados de cada questão. Com os dados alcançados, constatou-se que a hipótese levantada para o problema da pesquisa não foi atingida devido à complexidade do conceito de reincidência. Para trazer dados mais significativos sobre a realidade do PRC, foi reformulado o problema da pesquisa, a hipótese, bem como os objetivos geral e específico. Essa alteração foi devidamente encaminhada para o Comitê de Ética.

A coleta de dados foi realizada de duas maneiras:

$1^{\text {a }}$ - Documental: realizada na sala de assessoria jurídica, onde se liberou o acesso ao presídio para a pesquisadora, previamente autorizada pelo gestor da instituição. Os principais documentos pesquisados foram:

* Os processos de execução criminal (PEC);

*A lista de reeducandos, que se configura um instrumento utilizado pelo PRC no qual constam informações básicas sobre o recluso presente na instituição. Encontram-se nessa lista informações como: nome, sexo, I-PEN (sistema de identificação e administração prisional), data de entrada na instituição, artigo, comarca, pena (quantidade), regime, número de condenações, cor, grau de instrução, saída e progressão.

*O relatório informal interno, no qual constavam os dados estruturais sobre a instituição e o histórico de registro dos reclusos. Neste se encontram todas as infrações e delitos registrados em nome do recluso, bem como as informações sobre condenação, arquivamento do processo ou absolvição, enfim, toda a história prisional do recluso.

$2^{\mathrm{a}}$ - Pesquisa de campo: realizada com questionário autoaplicativo preenchido pelo próprio detento (exceto nos casos de analfabetos, em que a pesquisadora leu o instrumento e preencheu a resposta apontada pelo recluso separadamente). O preenchimento foi realizado de forma individual, na própria galeria onde o detento fica localizado e o instrumento foi preenchido à caneta azul, permitida por aquele estabelecimento. Os reclusos foram separados em pequenos grupos (10) para o preenchimento do questionário. Além disso, foi realizada uma entrevista com o gestor da instituição para saber sobre os programas de ressocialização vigentes no PRC no período de outubro de 2012.

\subsection{Instrumentos Utilizados}

1. Termo de consentimento livre esclarecido (detento).

2. Termo de consentimento livre esclarecido (gerente geral).

3. Questionário autoaplicativo.

\section{ASPECTOS ÉTICOS E CONSIDERAÇÕES FINAIS}


Revista Tecnologia e Ambiente, v. 21, 2014, Criciúma, Santa Catarina. ISSN: 1413-8131 (versão impressa) ISSN: 2358-9426 (versão eletrônica)

O projeto de pesquisa foi avaliado e aprovado pelo Comitê de Ética em Pesquisa da UNESC, de Criciúma, SC, e pela Comissão Nacional de Ética em Pesquisa (CONEP), baseado nas diretrizes e normas do Conselho Nacional de Saúde, sob a resolução 196/96, a qual regulamenta pesquisas envolvendo seres humanos. A privacidade dos participantes foi respeitada, sendo os dados obtidos utilizados somente para realização do estudo científico. O termo de consentimento livre e esclarecido foi assinado pelo gestor do PRC-SC, o qual se responsabilizou pela autorização da utilização dos dados para a pesquisa documental e pelos apenados que participaram da pesquisa de campo. Os reclusos reincidentes que participaram da pesquisa também precisaram assinar o termo de consentimento livre e esclarecido, que foi entregue e lido antes da aplicação dos questionários.

Depois foram analisados os resultados da pesquisa para entendermos como se dão essas relações sociais e qual a influência disso na questão da reincidência criminal. Alguns autores considerados fundamentais dentro desse contexto foram Foucault (2011), Goffmann (2007), Bauman (1998; 1999), entre outros.

Para alcançar os objetivos e responder ao problema da pesquisa, este trabalho foi estruturado da seguinte forma: iniciou-se com a fundamentação teórica, em que o primeiro capítulo abordou o sistema prisional e alguns subtópicos que auxiliaram no entendimento deste. O segundo capítulo falou da Psicologia Social, coadunada com a questão das prisões, além de trazer aspectos que envolvem a construção da subjetividade do sujeito, a pósmodernidade, a exclusão social e o vício de drogas, pontos estes que se mostram presentes ao longo da pesquisa. Num terceiro momento foram incluídas a metodologia de trabalho (de forma detalhada), a apresentação e a análise dos dados. Por fim, a conclusão, as referências bibliográficas e adicionados os apêndices e anexos referentes à pesquisa.

Como foi relatado na introdução, a questão da reincidência criminal é bastante complexa, sendo assim, seria interessante ir além. A mesma pesquisa, por exemplo, poderia ter sido realizada com toda a população do PRC, buscando comparar as diferenças entre aqueles considerados réus primários e os reincidentes.

Uma análise do histórico sobre os reclusos, que consta na instituição, com certeza, traria diversos debates sobre a questão da ressocialização no sistema prisional. Pesquisas qualitativas nessa área também se mostram bastante válidas, dando voz ao preso sobre a 
Revista Tecnologia e Ambiente, v. 21, 2014, Criciúma, Santa Catarina. ISSN: 1413-8131

(versão impressa) ISSN: 2358-9426 (versão eletrônica)

situação que enfrenta na instituição prisional e sua caminhada até ali, buscando analisar o processo de exclusão social.

Enfim, abordar essa questão prisional leva a imensas reflexões e debates, porém, acima de tudo, essas pesquisas mostram-se necessárias não apenas no papel, mas principalmente para mostrar o quão precário está o sistema prisional na atualidade, que é um reflexo da própria sociedade.

A criminalidade também é nossa responsabilidade enquanto ser social, pois aquele que está enclausurado em um presídio no dia de hoje poderá e deverá estar convivendo na sociedade no dia de amanhã. Excluí-lo, julgá-lo, estigmatizá-lo só irá reafirmar a criminalidade como sua única forma de defesa frente a uma exclusão que, em muitos casos, nunca teve chance de reverter.

\section{REFERÊNCIAS}

ADORNO, S.; BORDINI, E. Reincidência e reincidentes penitenciários em São Paulo: 1974 a 1985. RBCS, São Paulo, v. 9, n. 3, p. 70-94, fev. 1986.

ASSIS, R. D. de. A realidade atual do sistema penitenciário brasileiro. Revista CEJ, Brasília, ano XI, n. 39, p. 74-78, out./dez. 2007.

BARATTA, A. Criminologia crítica e crítica do direito penal: introdução à sociologia do direito penal. 3. ed. Rio de Janeiro: Revan, 2002. 254 p.

BARROS, A. M. de; JORDÃO, M. P. D. A cidadania e o sistema penitenciário brasileiro. Pernambuco: UNIEDUCAR, 2004. 20 p.

BAUMAN, Z. O mal-estar da pós-modernidade. Rio de Janeiro: Jorge Zahar, 1998. 137 p. . Globalização: as consequências humanas. Rio de Janeiro: Jorge Zahar, 1999. 145

p.

BENTO, A. Desemprego, pobreza e exclusão social. Coimbra: FEUC, 2010. 21 p.

BERGER, P. L.; LUCKMANN, T. A construção social da realidade: tratado de sociologia do conhecimento. 34. ed. Petrópolis, RJ: Vozes, 2012. 239 p.

BISSOLI FILHO, F. Estigmas da criminalização: dos antecedentes à reincidência criminal. Florianópolis: Obra Jurídica, 1998. 230 p.

BOCK, A. M. B. et al. Psicologias: uma introdução ao estudo de psicologia. 13. ed. Reform. e Ampl. São Paulo: Saraiva, 2008. 368 p.

BRASIL. Código penal, constituição federal e legislação penal. 16. ed. Rev. e Ampl. São Paulo: Revista dos Tribunais, 2011. 702 p. 
Revista Tecnologia e Ambiente, v. 21, 2014, Criciúma, Santa Catarina. ISSN: 1413-8131

(versão impressa) ISSN: 2358-9426 (versão eletrônica)

BUSATO, P. C. Antecedentes, reincidência e reabilitação à luz do princípio de Culpabilidade. Revista direito e liberdade, Natal, v.12, n. 6, 2009.

CANCLINI, N. G. A globalização imaginada. São Paulo: Iluminuras, 2007. 223 p.

CARLEN, P. A reclusão de mulheres e a indústria de reintegração. Revista Análise Social, Lisboa, v. XLII, n. 185, p.1005-1019, 2007.

CAVASSANI, S. M. C.; CUNHA, G. C. M. da. Relatório de pesquisa sobre o índice de reincidência dos apenados que cumpriram pena de prestação de serviço à comunidade. Espírito Santo: SEBRAE, 2006. Disponível em: <http://www.vepema.com.br>. Acesso em: 10 jul. 2012.

CONSELHO NACIONAL DE JUSTIÇA. Pesquisa sobre reincidência Criminal no Brasil. 2012. Disponível em: <http://www.cnj.jus.br/noticias/cnj/18527-ipea-pesquisarareincidencia-criminal-no- brasil>. Acesso em: 20 jun. 2012.

CONTE, M. et al. Consumismo, uso de drogas e criminalidade: riscos e responsabilidades. Psicologia: ciência e profissão, v. 27, n.1, p. 94-105, 2007.

DAMERGIAN, S. A construção da subjetividade na metrópole paulistana. In: TASSARA, T.O. Panoramas interdisciplinares para uma Psicologia Ambiental do Urbano. São Paulo: EDUC, 2001. 268 p.

DICIONÁRIO JURÍDICO. 2008. Disponível em: <http://www.direitonet.com.br/dicionario/exibir/741/Remicao-da-pena>. Acesso em: 20 maio 2013.

DUlliUS, A. A.; HARTMANN, J. A. M. Análise do sistema prisional brasileiro. Âmbito Jurídico, Rio Grande, v. XIV, n. 95, dez. 2011.

ERIKSON, E. H. Identidade, juventude e crise. 2. ed. Rio de Janeiro: J. Zahar, 1976. 322 p.

ESTIVILL, J. Panorama da luta contra a exclusão social: conceitos e estratégias. Portugal: STEP, 2003. $152 \mathrm{p}$.

ESTRELA, C. Violência em Santa Catarina. Disponível em:<http://noticias.uol.com.br/cotidiano/ultimas-noticias/2012/11/14>. Acesso em: 25 maio 2013.

FERNANDES, N. A falência do sistema prisional brasileiro. São Paulo: RG, 2000. 519 p.

FERREIRA, A. R. Crime-Prisão-Liberdade-Crime: o círculo perverso da reincidência no crime. Serviço Social \& Sociedade, São Paulo, n. 107, p. 509-534, jul./set. 2011.

FERREIRA, A. B. de H. et al. Novo dicionário Aurélio da língua portuguesa. 4. ed. Curitiba: Positivo, 2009. 2120 p.

FILHO, F.; LUIZ, L. Análise da relação da criminalidade e baixo nível escolar. Revista Intellectus: Rio de Janeiro, Ano VIII, n. 22, p. 103-118, out./dez. 2012.

FOUCAULT, M. Vigiar e punir: nascimento da prisão. 38. ed. Petrópolis: Vozes, 2011. $291 \mathrm{p}$. 
Revista Tecnologia e Ambiente, v. 21, 2014, Criciúma, Santa Catarina. ISSN: 1413-8131

(versão impressa) ISSN: 2358-9426 (versão eletrônica)

GIDDENS, A.; FIKER, R. As consequências da modernidade. São Paulo: UNESP, 1991. $177 \mathrm{p}$.

GIL, A. C. Métodos e técnicas de pesquisa social. 4. ed. São Paulo: Atlas, 1995. 207 p.

GOFFMANN, E. Manicômios, prisões e conventos. 7. ed. São Paulo: Perspectiva, 2007. $312 \mathrm{p}$.

GONÇALVES, M. da G. M. A psicologia como ciência do sujeito e da subjetividade: a historicidade como noção básica. In: BOCK, A. M. B. et al. Psicologia sócio-histórica: uma perspectiva crítica em psicologia. São Paulo: Cortez, 2001.

GÜNTHER, H. et al. Psicologia ambiental: entendendo as relações do homem com seu ambiente. Campinas, SP: Alínea, 2004. 196 p.

HARVEY, D. Condição pós-moderna: uma pesquisa sobre as origens da mudança cultural. 7. ed. São Paulo: Loyola, 1998. 349 p.

HOFFMANN, M. E. Psicologia, violência e organizações prisionais. In: ROVINSKI, S. L.; CRUZ, R. M. (Orgs.). Psicologia Jurídica. São Paulo: Vetor, 2009.

JACQUES, M. da G. C. Identidade e trabalho: Uma articulação indispensável. In: TAMAYO, A. et al. (Eds.). Trabalho, organizações e cultura. São Paulo, SP: Cooperativa de Autores Associados, 2006, p. 41-47.

LEOPARDI, M. T. Metodologia da pesquisa na saúde. Santa Maria, RS: Pallott, 2001. 296 p.

LOPES, J. R. "Exclusão social" e controle social: estratégias contemporâneas de redução da sujeiticidade. Psicologia \& Sociedade, v. 18, n. 2, p. 13-24, maio/ago. 2006.

LORENZER, A. Bases para uma teoria de la socialización. Buenos Aires, Amorrortu,1976.

MACEDO, K. B. et al. As relações do trabalho na era da globalização. Goiás: UCG, [s.d.]. 7 p. Disponível em: <http://www.ucg.br/site_docente/adm/katia_macedo/pdf/>. Acesso em: 2 abr. 2013.

MARIÑO, J. M. F. Análise comparativa dos efeitos da base socioeconômica, dos tipos de crime e das condições de prisão na reincidência criminal. Sociologias: Violências, América Latina, Rio Grande do Sul, Ano 4, v. 1, n. 8, jul./dez. 2002, p. 220-244.

MINISTÉRIO DA JUSTIÇA. Disponível em: <http://portal.mj.gov.br〉. Acesso em: 18 jun. 2012.

MORAES, J. M. Pós-modernidade: Uma luz que para uns brilha e para outros ofusca no fim do túnel. Revista Veiga Mais, Ano 3, n. 5, 2004.

MOREIRA, L. A.; ROSA, P. M. da. A modificação da nova lei de drogas como um dos fatores de aumento da criminalidade no município de Maringá. In: PEIXE, B. C. S. et al. (Orgs.). Políticas Públicas no Estado do Paraná: Resumos de Propostas e Projetos. Cascavel: EDUNIOESTE, 2010. 243 p.

MYERS, D. G. Psicologia social. 6. ed. Rio de Janeiro: LTC, 2000. 422 p. 
Revista Tecnologia e Ambiente, v. 21, 2014, Criciúma, Santa Catarina. ISSN: 1413-8131

(versão impressa) ISSN: 2358-9426 (versão eletrônica)

NETO, E. H.; BAUMER, S. Ressocialização de Detentos: Mito ou Realidade? Comparação das percepções dos detentos do Presídio Industrial e o mercado de trabalho turístico de Joinville - SC. In: SEMINÁRIO DE PESQUISA EM TURISMO DO MERCOSUL, 5., 2008, Caxias do Sul. Anais... Caxias do Sul: Universidade de Caxias do Sul, 2008.

NUNES, L. M.; JÓLLUSKIN, G. Drogas e Comportamentos de Adicção: Um manual para estudantes e profissionais de saúde. Porto: Universidade Fernando Pessoa, 2010.

PAPALIA, D. E. et al. Desenvolvimento Humano. 8. ed. Porto Alegre: Artmed, 2006. 888 p.

PINTO, S. L. de A. A socialização humana e a internalização da cultura. Revista Intinerarius Reflectionis, Goiás, v. 1, n. 2, p. 11-32, jan./jul. 2006.

PRÁ, A. et al. Pesquisa do perfil sócio demográfico e criminal dos presos no estado do Paraná sob o ângulo da reincidência. Paraná: SEJU, 2004. 93 p.

RIZZO, B. E. Sistema prisional brasileiro, uma crise oculta. 2007. Disponível em: <http://ofca.com.br/artigos>. Acesso em: 5 abr. 2013.

RODRIGUES, A. Psicologia social. 17. ed. Petrópolis: Vozes, 1998. 485 p.

RUBI, M. P. et al. Profissional da informação: aspectos de formação, atuação profissional e marketing para o mercado de trabalho. Informação \& Sociedade, João Pessoa, v.16, n.1, p. 79-89, jan./jun. 2006.

SILVA, A. J. da. Lei de execução penal: interpretada pela jurisprudência dos tribunais de justiça. 2. ed. Curitiba: Juruá, 2007. 209 p.

SILVA, D. P. Dicionário Jurídico Conciso. Rio de Janeiro, RJ: Forense, 2008. 749 p.

SOUZA, L. C. G. de. O ensino da psicologia social e suas representações: a formação do saber e o saber em formação. 2005. [Tese de Doutorado] - Universidade Federal do Rio de Janeiro, Rio de Janeiro, 2005.

SOUZA, R. C. N. de. Violência e criminalidade relacionadas ao uso indevido de drogas pelos menores de rua do centro histórico de salvador. Salvador, BA: RENAESP, 2009. 36 p.

THOMPSON, A. A questão penitenciária. 5. ed. Rev. e Atual. Rio de Janeiro: Forense, 2002. 148 p.

VIANNA, F. B.; REIS, S. A. A interação do apenado na Cadeia Pública de Poços de Caldas-MG. Psicologia em Revista, Belo Horizonte, v. 16, n. 3, p. 557-574, dez. 2010.

WACQUANT, L. As prisões da miséria. Rio de Janeiro: Jorge Zahar, 2001. 121 p.

WOODWARD, K. Identidade e diferença: uma introdução teórica e conceitual. In: SILVA, T. et al. Identidade e diferença: a perspectiva dos estudos culturais. 4. ed. Petrópolis: Vozes, 2005, p. 7-72. 